\title{
Large penile plexiform neurofibroma in an 11-year old boy
}

Nwokoro Chingbundu Collins ${ }^{1}$, Emmanuel Ezekiel Ayodeji ${ }^{2}$, Fatungase Oluwabunmi Motunrayo', Salami Babatunde Abayomi', Ogundele Ibukunolu Olufemi, ${ }^{1}$ Amosu Lukmon Olusesan ${ }^{1}$

Date Received: 31 July 2017

Revision Received: 22 November 2017

Date Accepted: 8 December, 2017

Correspondence:

Chingbundu Nwokoro

(collinsnwokoro@gmail.com

1. Paediatric Surgery Unit, Department of Surgery, OlabisiOnabanjo University Teaching Hospital, Sagamu

2. Department of Anaesthesia and Intensive Care, Olabisi Onabanjo University Teaching Hospital, Sagamu

\section{Background}

Abstract

Neurofibromatosis is a genetically inherited disorder of the nervous system (brain and spinal cord) which mainly affects the development of nerve (neural) cell tissues, causing tumors (neurofibromas) to develop on nerves. It is the most common single gene disorder of the nervous system and inheritance is through autosomal dominance. They are usually classified into types 1 and 2 , the type 1 is the commoner type and also known as superficial neurofibroma. Plexiform neurofibromas are the next most common type of tumor in individuals with type 1 neurofibroma. Plexiform neurofibromas are histologically benign tumors that are made up of a variety of cell types including neuronal axons, Schwann cells, fibroblasts, mast cells, macrophages, perineural cells and extracellular matrix materials such as collagen. They can occur in any part of the body and can grow throughout the person's lifetime, often becoming disfiguring, disabling or deadly via compression of vital structures or conversion to a malignant sarcoma or malignant peripheral nerve sheath turmor. The aim of this report is to present a large penile plexiform neurofibroma which required extensive dissection for complete excision and reconstruction of the phallus and glans penis.

Objectives

To present a huge penile plexiform neurofibroma and the mode of surgical treatment.

Methods

The huge penile plexiform neurofibroma was completely excised and the penile defect resulting from the excision was repaired.

Conclusion

Plexiform neurofibromas are congenital tumors of peripheral nerve sheaths which may also develop near nerve roots deep within the body. They are usually benign but carry a malignant potential in 5-10\% of patients. Plexiform neurofibromas are commoner in the face, chest and limbs but the index case occurred on the penile shaft.

\section{Introduction}

Neurofibromatosis $(\mathrm{NF})$ is one of the most common genetic disorders. It is inherited in an autosomal dominant fashion and it is classified into two genetically distinct subtypes characterized by multiple cutaneous lesions and tumours of the peripheral and central nervous system such as multiple cafe au lait spots, cutaneous neurofibromas, plexiform neurofibromas, bony abnormalities, spinal cord compression, duralactasia, learning disabilities, attention deficit, headaches, seizures, brain tumors and deafness ${ }^{1}$. Neurofibromatosis- 1 is caused by a heterozygous mutation in the NF-1 gene, which codes for the protein neurofibromin and results in a loss of functional protein. The NF-1 gene regulates the expression or deregulation of the protein neurofibromin.

Neurofibromin function is not completely understood but it is thought to down-regulate a cellular proto-oncogen that is an important regulator of cell growth. Therefore, neurofibromin plays a role in the control of cell division and possesses certain tumor suppression qualities; hence, loss of neurofibromin through mutation leads to an increased risk of developing benign and malignant tumours in affected individuals $^{2}$. Neurofibromatosis type 2 (NF-2), previously termed central neurofibromatosis is much rarer occurring in less than 1 in 25,000 individuals. It often presents with signs of sudden loss of hearing due to the development of bi or unilateral vestibular schwannomas ${ }^{2,3}$.

Plexiform neurofibromas (PNFS) are benign nerve tumour resulting from aberrant growth of the cells of nerve sheath. They are usually congenital, but they may instead present during the first year as a subtle soft-tissue enlargement or a large patch of cutaneous hyperpigmentation. They occur in at least $50 \%$ of patients with neurofibroma NF-1 and are probably present at birth. Many are asymptomatic and the exact timing of growth of plexiform tumours is unpredictable $e^{4,5}$. Presenting symptoms depend on the location of the tumours. Tumours of the head, neck and face are most common followed by disfigurement and lesions of the spine, extremities and abdomen ${ }^{6}$. They often arise from the dorsal spinal roots, nerve plexi, large peripheral or sympathetic chains. Plexiform tumours may be discrete, homogenous and well circumscribed or diffuse, heterogeneous and infiltrative. They may involve superficial skin or be entirely internal ${ }^{4}$.

Early, childhood, puberty and child bearing age are considered to be the periods of greatest risk for disease progression ${ }^{6,7}$. Furthermore, PNFS have a potential for transformation into highly malignant peripheral nerve sheath tumours, which occur in approximately $5 \%$ of patients ${ }^{8}$. The index case is a large penile growth with severe distortion of the external genitalia.

\section{Case Presentation}

The index patient was an 11 year-old boy who was brought to our out-patient clinic on account of a penile swelling of 11 years duration. The penile swelling was noticed two weeks 
after he was circumcised during neonatal age. The swelling showed progressive increase in size over the period that it existed. He had no swelling in other parts of his body. There was neither associated dysuria nor change in frequency of micturition. There was no history of chronic constipation, abdominal mass, obstructive lower urinary tract symptoms and history of bone and joint pains. He also had no history of seizures, anorexia, weight loss, visual and hearing impairment.

Physical examination revealed a healthy looking boy, not pale, anicteric, afebrile, acyanosed, and not dehydrated. Genitourinary examination revealed an abnormally looking male external genitalia with a large hyperpigmented, firm, nodular, non-tender swelling over the dorsal aspect of the penile shaft and a nodule on the glans penis. (Fig.1) The external urethral meatus remained intact. Both corpora cavernosum and spongiosum were palpable and not attached to the mass. The testes were palpable in the scrotum. Other systemic examinations were essentially normal. Of particular note was the absence of cafe au lait spots on the boy's trunk (fig 2).

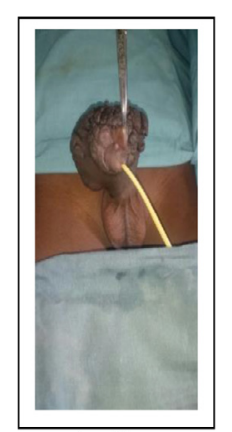

Figure 1: Plexiform neurofibroma

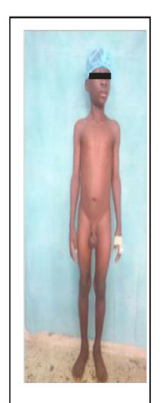

Figure 2: Patient's trunk without cafe au lait spots

A provisional diagnosis of Penile Plexiform Neurofibroma was made and he was subjected to the following

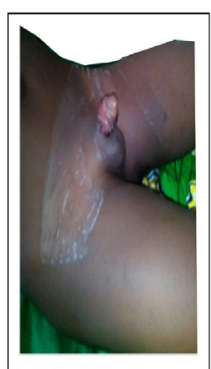

Figure 3: Post-operative appearance of the external genitalia after total excision of the perile mass on the glans penis.

He had total excision of the mass and reconstruction of the penile shaft under general anaesthesia. The excision of the mass commenced with an inverted v-incision which was placed at the superficial margins of the mass and this was deepened down to its attachment to the bucks fascia. Total excision of the mass was possible because there was a clear margin between the mass and the bucks fascia. The nodule on the glans penis was removed through a wedge incision. The penile shaft was reconstructed through tissue apposition and use of island flaps. He had a successful post-operative care and was discharged home to continue further care and follow-up at the paediatric surgical out-patient clinic. The histology report of the specimen excised at surgery revealed a benign neurofibroma.

\section{Discussion}

Neurofibromatosis comprises at least two separate genetic disorders (NF-1 and NF-2) characterized by the formation of tumours surrounding nerves and a variety of other pathological features. The most common type (NF-1), accounting for $90 \%$ of cases, is characterized by multiple café-au-lait spots and the occurrence of neurofibroma along peripheral nerves. The penetrance of NF-1 or the proportion of people with the NF-1 gene with a clinical presentation of the disorder is close to $100 \%$, while NF type 2 is associated with bilateral acoustic neuromas which may lead to hearing loss starting as early as the teenage years ${ }^{9,10}$.

The manifestations of neurofibromatosis had been observed for a long time before being described by Robert William Smith in 1849. However, the classic description was given by a German pathologist, Friedrich Daniel Von Recklinghausen, who accurately described the diverse findings as a single entity in 1882; thus the condition is often referred to as Von Recklinghausen's disease ${ }^{11}$. There is no single commonly accepted classification but the most widely accepted classification are four recognized forms of neurofibromatosis; neurofibromatosis type 1, bilateral acoustic neurofibromatosis (or neurofibromatosis type 2, or central neurofibromatosis), segmental neurofibromatosis and cutaneous neurofibromatosis. Neurofibromas are the most common benign tumours of NF-1. They can develop at any point along a nerve and often form by late adolescence. These tumours are nodular and may be firm to soft to touch. Three sub-types of neurofibromas exist; cutaneous, subcutaneous and plexiform. Cutaneous and subcutaneous varieties are not specific for neurofibromatosis whereas the plexiform variety is specific for the disease ${ }^{12}$.The diagnostic criteria of neurofibromatosis type- 1 are two of seven cardinal clinical features:

Six or more café-au-lait macules over $5 \mathrm{~mm}$ in greatest diameter in pre-pubertal individuals and over $15 \mathrm{~mm}$ in greatest diameter in post-pubertal individuals, two or more neurofibroma of any type or one plexiform neurofibroma, freckling in the axillary or inguinal region, optic glioma, two or more Lisch nodules, a distinctive osseous lesion like sphenoid wing dysplasia or thinning of the long bone cortex with or without pseudoathrosis and a first degree relative with NF-1 ${ }^{13}$. Plexiform neurofibromas are uncommon and occur almost exclusively in about 5-15\% of patients with neurofibromatosis - Type 1. Two types of plexiform neurofibromas have been recognized; (i) diffuse/ elephantiasis neurofibromatosis and (ii) nodular type. Plexiform neurofibroma is a non-circumscribed, thick and irregular benign tumor of the peripheral nerve sheath. It is a virtually pathognomonic and often disabling feature of neurofibromatosis type 1 . They may spread out just under the skin or deeper in the body. They originate from nerve sheath cell, subcutaneous or visceral peripheral nerves and can involve multiple fascicles ${ }^{14,15}$.

The overlying skin is hyperpigmented with hypertrichosis and has a bag of worms feeling on palpation. It invades into the surrounding soft tissue and causes bony hypertrophy. A rapid growth occurs during adolescence with a period of relative inactivity in the adults ${ }^{16}$. However, the index case involved the peripheral nerves of the penis. The tumor in this patient was quite large and disfigured the external genitalia.

Although, characteristically benign, plexiform neurofibromas can cause pain, disfigurement, nerve root and spinal cord 
compression and vertebral erosion and functional changes and more importantly, may turn into highly malignant peripheral nerve sheath tumours in approximately $5 \%$ of patients ${ }^{8,17}$.

The index case had no café au lait spots, no pain and no functional impairment and the histology report revealed a benign lesion. He was investigated through abdominal ultrasonography, chest radiography, full blood count and urinalysis; which revealed normal findings. His visual acuity was also found to be normal. Clinical management of plexiform neurofibroma requires a multidisciplinary approach and the involvement of a multi-specialty neurofibromatosis clinic. However, current treatment of plexiform neurofibroma has remained largely surgical since there has been no accepted effective medical treatment ${ }^{18,19,20}$. Most authors suggest early resection of smaller tumours which may minimize the extent of local involvement ${ }^{21,22}$ The risk of re-growth of resected asymptomatic tumors has also been highlighted by some authors ${ }^{23,24}$. Complete resection of a giant benign tumor is usually difficult but is important in minimizing cosmetic deformities ${ }^{25}$. The index case had a successful total excision of the large plexiform neurofibroma and re-construction of the phallus and glans penis. One year post-excision follow-up visit to our health facility revealed normal appearing external genitalia with no obvious functional disability. In general, patients with NF-1 and NF-2 should undergo yearly neurologic and ophthalmologic examinations.

Plexiform neurofibromas are congenital tumors of peripheral nerve sheaths which may also develop near nerve roots deep within the body. They are usually benign but carry a malignant potential in $5-10 \%$ of patients. Plexiform neurofibromas are commoner in the face, chest and limbs but the index case occurred on the penile shaft.

\section{Conclusion}

Plexiform neurofibromas are congenital tumors of peripheral nerve sheaths which may also develop near nerve roots deep within the body. They are usually benign but carry a malignant potential in $5-10 \%$ of patients. Plexiform neurofibromas are commoner in the face, chest and limbs but the index case occurred on the penile shaft.

Informed consent was obtained. No conflict of interest.

\section{Acknowledgment}

We wish to express our appreciation to Mr. Obafemi Abiodun for his numerous contributions towards the writing of this case report.

\section{References}

1.Gerber PA, Autal AS, Neumann NJ, Homey B, Matuscheck C, Peiper M, et al. Neurofibromatosis Eur J Med Res. 2009; 14:102. doi: 10.1186/2047-783X-14-3-102.

2.Ghalayani P, Saberi Z, Sardari F. Neurofibromatosis type 1 (Von Recklinghausen's disease: A family case report and literature review. Dent Res J (Isfahan) 2012; 9:483-8.

3.Boyd, Korf BR. Theos A. Neurofibromatosis type I. JAM AcadDermatol 2009;61:1-16.

4.Mantner V F, Hartmann M, Kluwe L, Friedrich R E, Finsterer C (MR). Growth patterns of plexiformneurofibromas in patients with neurofibromatosis type 1. Neuroradiology. 2006;48:160-165.

5.Sonja A. R, Friedman J.M. NFI Gene and Neurofibromatosis 1. AM. J. Epidermal 2000;151:33-40.
6.Staser K, Yang FC, Clapp DW. Pathogenesis of plexiform neurofibroma: Tumor-stromal/hematopoietic interactions in tumor progression. Annu Rev Pathol 2012;7:469-95.

7.Jesoph E.C., Dolphine O. PlexiformNeurofibromas clinically consistent with neurofibromatosis Type 1: A case report Rev. declin. Pesq. Odontol, 205;1:15-21.

8.Evans DG, Baser ME, MC Gaughran J, Shari F S, Howard E, et al. Malignant peripheral sheath tumos in neurofibromatosis 1 . J Med Genet. 2002;39:311-314.

9.Ferner RE, Huson SM, Thomas N, et al. Guidelines for the diagnosis and management of individuals with neurofibromatosis 1. Jmed Genet. 2007;44:81-88.

10.Gordon P.G, Phillip A.T, Russel G.M, Richard K.S, David BC. Hypertension and Neurofibromatosis Case Report. Hypertension 1982;4:984-897.

11.Ferner RE. Neurofibromatosis 1 and Neurofibromatosis 2: A twenty first century perspective. Lancet neurol. 2007;6:340-351.

12.Fermer RE, Huson SM, Thomas N, Moss C, Willshaw H, Evans DG et al. Guidelines for the diagnosis and management of individuals with neurofibromatosis 1. J Med Genet 2007;44:81-8.

13.Neurofibromatosis. Conference Statement. National Institutes of Health Consensus Development Conference. Arch Neurol 1988;45:5758 .

14.Durrani AA, Crawford AH, Chouhdry SN, Saifuddin A, Morley TR. Modulation of spinal deformities in patients with neurofibromatosis type I. Spine (Philapa 1976) 2000; 25:69-75.

15.Jetf K, Friedman J.M., Clinical and Genetic Aspects of Neurofibromatosis 1.Genet Med. 2010;12:1-11.

16.Huson SM, Harper PS, Compston D. Von Recklinghausen neurofibromatosis a clinical and population study in south - east Wales. Brain 1988;111:1355.

17.King A A, Debaun MR, Riccardi VM, Autmann DH. Malignant peripheral sheath tumors in neurofibromatosis 1. AM J Med Genet.2000;93:388-392.

18.Gutman DH, Aylsworth A, Carey JC, Korf B, Marks J, Pyeritz RE, et al. The diagnostic evaluation and multidisciplinary management of neurofibromatosis 1 and neurofibromatosis 2. JAMA 1997,278:51-57.

19.Yi J, Bing X, Xuejun W, Wenying L, Siyuan C. Surgical treatment of giant plexiform neurofibroma associated with pectus excavatum. J Cardiothorac Surg. 2011; 6:119. doi: 10.1186/1749-8090-6-119

20.Valentina Dimitrova, Ivelina Yordanova, Verka Pavlova, Valentin Valtchev, Dimitar Gospodinov, Boryana Parashkevov, et al. A case of neurofibromatosis type 1 . Journal of IMAB 2008, 14:63-66 J of IMAB 2008;14:63-67. doi: 10.5272/jimab.14-1-2010.63

21.Nguyen RPlexiform Neurofibromatosis in children with Neurofibromatosis Type I: Frequency and Associated Clinical Deficits. J Pediatr, 2011;159(4):652-5.e2. doi: 10.1016/j.jpeds.2011.04.008

22.Virginia C.W, John L, Michael A.B David H.G. Neurofibromatosis type 1 revisited. Pechatrics 2009;123:124-133. doi: 10.1542/peds.20073204

23.Kudur $\mathrm{MH}$, Hulmani M. Isolated plexiform neurofibroma over left palm: A case report and review of literature. Indian J Dermatol 2013;58:245. doi: 10.4103/0019-5154.110883

24.Boulanger JM, Larbrisseau A.. Neurofibromatosis type 1 in a pediatric population: Ste-Justine's experience. Can. J. Neurol. Sci.. 2005;32:225-231. https://doi.org/10.1017/S0317167100004017

25.Friedrich RE, Schmelzle Hartmann M, Mautner VF: Subtotal and total resection of superficial plexiform neurofibromatosis of face and neck. Four case reports. J Craniomaxillofac Surg.. 2005;33:55-60. doi: 10.1016/j.jcms.2004.08.004 